\title{
Expectations, Experiences, and Satisfaction of the Graduate Students with Distance Online Learning Environment in OMSC Graduate School during the Covid-19 Pandemic
}

\author{
Venessa S. Casanova (Corresponding author) \\ Graduate School, Occidental Mindoro State College, Labangan Poblacion, San Jose, Occidental Mindoro,Philippines \\ Email: venessacasanova@gmail.com \\ Wenceslao M. Paguia \\ Graduate School, Occidental Mindoro State College, Labangan Poblacion, San Jose, Occidental Mindoro, Philippines
}

Received: $16 / 08 / 2021$

Accepted: 22/11/2021

Published: 01/01/2022

Volume: 3 Issue: 1

How to cite this paper: Casanova, V. S., \& Paguia, W. M. (2022). Expectations, Experiences, and Satisfaction of the Graduate Students with Distance Online Learning Environment in OMSC Graduate School during the Covid-19 Pandemic. Journal of Practical Studies in Education, 3(1), 14-22

DOI: https://doi.org/10.46809/jpse.v3i1.39

Copyright (C) by author(s) and Global Talent Academy Ltd. This work is licensed under the

Creative Commons Attribution International License (CC BY 4.0).

http://creativecommons.org/licenses/by/4.0/

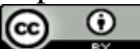

\begin{abstract}
This descriptive study determined the level of expectations, experiences, and satisfaction of the graduate students with distance online learning environment in Occidental Mindoro State College Graduate School during the Covid-19 pandemic. The study was conducted from January 2021 until August 2021 at OMSC Labangan Campus, San Jose, Occidental Mindoro, Philippines. A total of 58 respondents selected through a simple random sampling technique participated in the study. The questionnaire was the main instrument used in gathering data for the study. Data gathered were analyzed using frequency and percentage, weighted mean, Pearson-r moment correlation, and Regression analysis. It was found that the level of expectation, the extent of the learning experience, and the level of satisfaction with the online learning environment of the graduate school are very high. There is a high positive correlation between expectations, experience, and satisfaction. Experience has a high positive correlation with satisfaction. None of the indicators of expectation influenced satisfaction. The social and cognitive presence influence the satisfaction of the graduate students with the distance online learning environment of the OMSC Graduate School. It was suggested to improve internet connectivity, use asynchronous and modular delivery modes of instruction, give feedback and return students' output, and the faculty must keep up their good work to improve the distance online learning environment. It was concluded that graduate student's expectation and experience greatly influence their level of satisfaction with the online distance learning environment. Concrete actions are needed to improve and optimize the processes in the distance learning environment to enhance students' experiences and increase satisfaction.
\end{abstract}

Keywords: Expectations, Experiences, Satisfaction, Distance learning, Online Learning Environment

\section{Introduction}

The accelerated technology evolution and the social transformation of nations have opened space for new educational paradigms to emerge and make the learning process centered on the student (Lemos \& Pedro, 2012). Modern technologies are contributing to the dissolution of traditional classroom boundaries. Students connect with their instructors and each other 
through modalities of almost every variety, greatly expanding avenues of communication (Dziuban et al., 2015). According to Kusel, Martin, \& Markic ( 2020), online teaching has been used for more than two decades in tertiary education. It can make higher education more attractive, individualized, practical, and flexible, enabling it to respond to the challenges faced by universities. Online teaching encompasses innovative learning formats such as blended learning, flipped classroom, social and collaborative learning, simulations and game-based learning, synchronous and asynchronous video lectures, polling software, or collaboration authoring tools. It also includes designing and delivering courses with a learning management system (LMS), massive open online courses (MOOCs), and the provision of materials such as open educational resources (OERs).

In March 2020, Covid -19 impacted individuals' private lives with strict limitations and resulted in enormous changes in teaching and learning in higher education. As a result, most countries worldwide have temporarily closed educational institutions to reduce the spread of the Covid-19 virus. However, learning has not stopped but is now fully online as schools and universities provide remote schooling (Di Pietro, Biagi, Costa, Kapinski, \& Mazza,2020). Furthermore, universities needed to change their teaching practices due to Covid -19 pandemic (Kusel, Martin, \& Markic,2020). As a result, many countries started offering online teaching to students to promote online education and restore the regular teaching order (Chen, Peng, Yin, Rong, Yang, \& Cong, 2020).

In the OMSC Graduate School context, the transition from the traditional classroom to online learning started in the Summer of 2020. Faculty and students have utilized online distance learning platforms such as google meet, zoom, messenger, Facebook, and other social media applications for almost five semesters already. In carrying out online distance education during this pandemic, it has been observed that this transition has also brought setbacks to its administration, employees, teachers, and students.

Chen (2020) stated that in carrying out online education during the Covid -19 pandemic, many new problems arise in online distance learning, requiring new factors affecting user satisfaction to be considered in the study. Lemos \& Pedro (2012) also stated that despite the increase in e-learning initiatives, there is still reduced knowledge regarding these experiences from students' perspectives even though they are the central elements of the educational process. Furthermore, few studies have focused on students' general level of satisfaction and even fewer on their previous expectations and how they impact students' evaluation of their level of satisfaction. Gopal, Singh, and Aggarwal (2021) stated that none of the studies had examined the effect of course design, quality of the instructor, prompt feedback, and students' expectations on students' satisfaction with online classes during the pandemic period of Covid-19. This study will help characterize the different dimensions of online distance learning that need to be considered. Lemos \& Pedro ( 2012) stated that these dimensions and indicators are beneficial for the quality assurance process regarding e-learning initiatives in Higher Education Institutions (HEIs). It is crucial to know which factors influence student expectation and satisfaction in distance learning or web-based learning because they can be used as regulatory indicators of the adequacy of the course design and the fitness of the virtual learning environment. They can also help identify effective strategies and services for students' online support. Results of this study may serve as a basis for future studies regarding the factors that contribute to disengagement and engagement of graduate students in online learning. In addition, it may be used as a reference in research on the teaching strategies employed by graduate school faculty that promote online learning engagement and in crafting policies and activities that will help increase the online learning engagement of the graduate students. Thus, this study is conducted.

This study aimed to determine the expectation, experiences, and satisfaction in the Online Distance Learning environment of the Graduate Students of OMSC Graduate School. Specifically, it:

1. Determined the level of expectations of the graduate students with Online Distance Learning environment in terms of :
a. Technological infrastructure
b. Course Professor
c. Learning modalities
d. Course design
e. Evaluation system

2. Find out the experiences of the graduate students with Online Distance Learning environment in terms of :

a. Teacher presence

b. Social presence

c. Cognitive presence

3. Ascertain the graduate students' level of satisfaction with the Online Distance Learning environment in terms of:

a. Technological infrastructure

b. Course professor

c. Learning modalities

d. Course design

e. evaluation system

4. Test if there is a significant relationship between graduate students' expectations, experiences, and satisfaction with the Online Distance Learning environment.

5. Identify which indicators of expectations and experiences significantly influence the respondents' level of satisfaction with the Online Distance Learning environment. 
6. Suggest ways on how the online distance learning environment of OMSC Graduate School can be improved.

\section{Theoretical Framework}

The theoretical premise of the study is reflective of the Expectation Confirmation Theory (ECT). It examines how consumers' expectations, when coupled with satisfaction, might impact future purchasing decisions. The theory suggests that satisfaction will result when a product or service outperforms expectations (positive disconfirmation). On the other hand, dissatisfaction will result when a product fails to meet expectations (negative disconfirmation) ( Bailie, 2015). In the higher education context, HEIs who offer online distance learning must consider the expectations and experiences of the students so that all the educational undertakings of the HEIs will be geared towards the attainment of the highest level of student satisfaction.

The student's extent of experiences with the distance online learning environment is anchored on Garrison, Anderson, and Archer's Community of Inquiry (COI) framework. The Community of Inquiry theoretical framework represents a process of creating a deep and meaningful (collaborative-constructivist) learning experience through the development of three interdependent elements - social, cognitive, and teaching presence (Garrison, Anderson, and Archer, 2000).

The possible relationship between student satisfaction with online learning can be explained using Argyris's theory of psychological contracts in 1960. It states that these contracts are formed by implicit understanding and are not bound by written or legal agreements of two parties within a reciprocal relationship. They consist of perceived obligations and expectations, and thus, are subjective and vary from person to person. When broken or breached, satisfaction and performance decline, and workforce turnover increases, impacting attitudes and behaviors (Dziuban, Moskal, Thompson, Kramer, De Castro, \& Hermsdorfer, 2015).

Conducting Online Distance Learning is anchored on Moore's Transactional Distance Learning. It explains the interaction among learners, teachers, and course structure and how it affects the learning environment. Distance education is characterized by the transaction that occurs when there is a separation of time and space between learner and teacher, a separation that leads to unique patterns of learner and teacher behaviors ( Nwanko,2015).

\section{Conceptual Framework}

The framework that guided this study is presented in Figure 1 below. The paradigm shows the relationship between the level of expectations, experiences, and level of satisfaction in the distance online learning environment of the OMSC Graduate School. Knowing prospective learners' requirements before offering the course would be beneficial to meet the learners' expectations. The key areas on which the learner needs to be analyzed are learning objectives, prior knowledge, expected outcomes, technical requirements or limitations, and learning preferences. If the requirements above are met, learner satisfaction with e-learning becomes key for success (Sunkara \& Kurra,2017). According to Lemos and Nueva (2012), dimensions such as course design, coordination, faculty, and tutors; curricular program; resources learning methodologies, evaluation system, support services, and technological infrastructure have a significant relationship between e-learning students' expectations and their level of satisfaction.
IV
DV/IV
DV

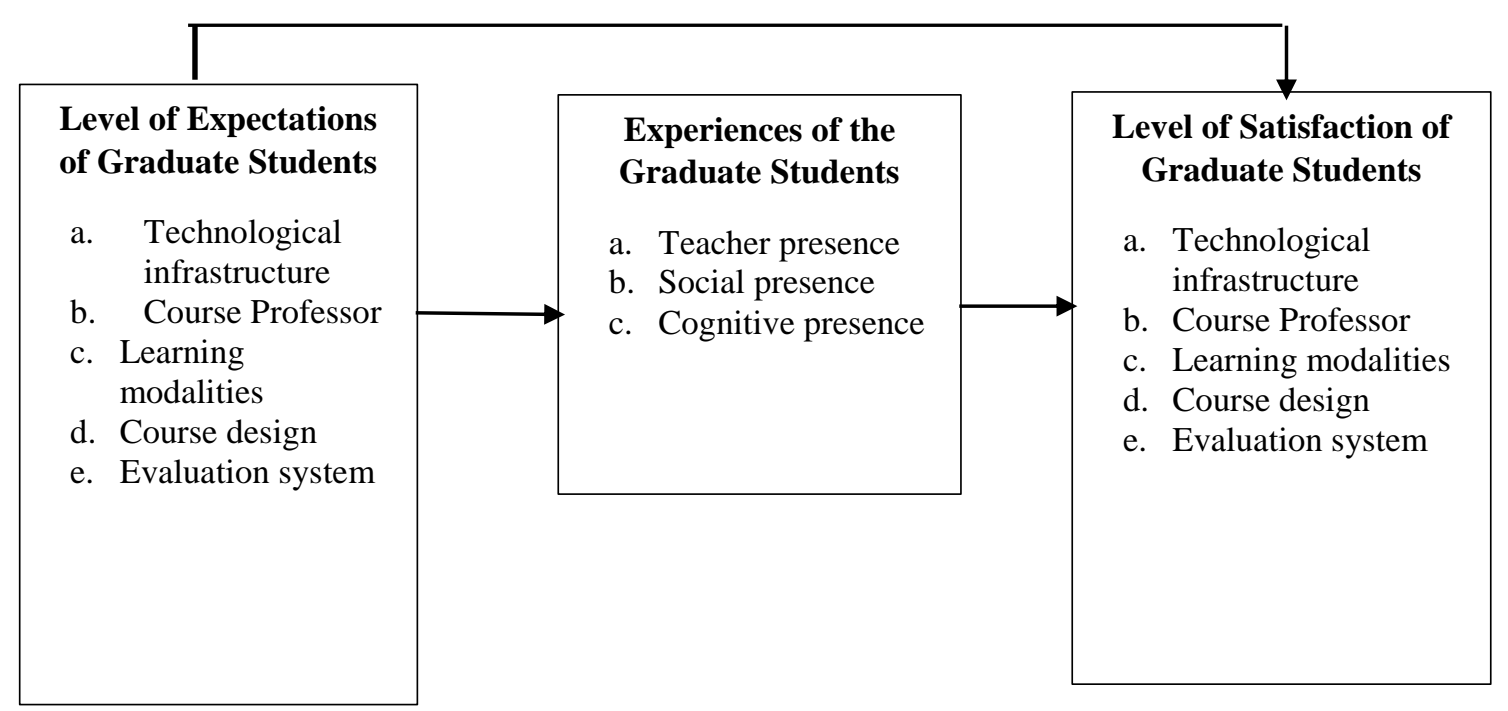

Figure 1. Research paradigm 


\section{Methodology}

This study utilized descriptive research designs to determine the respondents' expectations, experiences, and satisfaction with Online Distance Learning in the OMSC Graduate School during the Covid-19 Pandemic. A total of 58 randomly selected graduate students were the respondents of the study. The study was conducted at OMSC Graduate School in Labangan, San Jose, Occidental Mindoro, from January 2021 until August 2021. Survey questionnaires were the main instrument in gathering data for the study. The survey instrument of Lemos and Nueva (2012) was adapted to measure the respondents' level of expectations and satisfaction. In addition, it was modified to suit the needs of the current study. The Community of Inquiry Questionnaire of Arbaugh et al. (2008) was used to measure the extent of experiences of the respondents in the distance online learning environment. It was sent to the respondent's email and messenger. Data collected were recorded, tabulated, and analyzed using descriptive statistics such as frequency and percentage, weighted mean, Pearson-r Moment Correlation, and Regression Analysis.

\section{Results and Discussion}

\subsection{Level of Expectations of the Graduate Students with the Online Distance Learning Environment}

Arslan, Daghan, and Akkoyunlu (2020) stated that having knowledge and understanding of student expectations and how these expectations affect student performance and retention is the first step in developing programs that will help students develop realistic expectations for online courses.

Table 1 reveals that the graduates have very high expectations from the Graduate School of OMSC (4.51). In addition, the graduates have very high expectations in terms of course professor (4.58), learning methodologies (4.57), and course design (4.53).

The findings imply that the course professors are accessible and approachable and provide encouragement and guidance in online discussion and sharing of ideas. The learning methodologies encourage research-skills development and provide stimulation of online interaction between faculty and students. The course design provides involvement and a sense of community promoted among students. It also has adequacy of the technology and platform used. The Expectation Confirmation Theory (ECT) states that satisfaction will result when a product or service outperforms expectation (positive disconfirmation). On the other hand, dissatisfaction will result when a product fails to meet expectations (negative disconfirmation) (Bailie, 2015). In the higher education context, HEIs who offer online distance learning must consider the expectations and experiences of the students so that all the educational undertakings of the HEIs will be geared towards the attainment of the highest level of student satisfaction.

Table 1. Level of expectations of the graduate students with the online distance learning environment

\begin{tabular}{ccc}
\hline Indicators & Mean & Description \\
\hline Technological Infrastructure & 4.36 & High \\
Course Professor & 4.58 & Very High \\
Learning Methodologies & 4.57 & Very High \\
Course Design & 4.53 & Very High \\
Evaluation System & 4.49 & High \\
Expectations & 4.51 & Very High \\
\hline
\end{tabular}

Scale: 1.00-1.50 Very Low; 1.51-2.50 Low; 2.51-3.50 Moderate; 3.51-4.50 High; 4.51-5.00 Very High

\subsection{The Extent of Experience of the Graduate Students with the Online Distance Learning Environment in OMSC Graduate School}

In documenting the extent of experiences of the graduate students with online distance learning, the Community of Inquiry (CoI) framework by Garrison, Anderson, \& Archer was used. This framework highlights social presence, teaching presence, and cognitive presence as essential elements to facilitate successful educational experiences in online distance learning environments (Bektashi, 2018). Cognitive presence is how the instructor provides opportunities for students to interact with the material in robust, thought-provoking ways. Social presence refers to building a community of learning that incorporates student-to-student interactions. However, teaching presence includes everything the instructor does-structuring the course, providing lectures, explaining assignments, creating rehearsal opportunities, supplying tests, grading, answering questions, and so on ( Van Wart, Ni, Medina, et al., 2020).

Table 2 shows that the extent of experiences of graduates in the Graduate School is very high (4.58). In addition, the graduates have very high experiences in teaching presence (4.70) and cognitive presence (4.57), and high experiences in social presence.

The findings imply that the graduate school professors established cognitive or emotional connections between physically separated learners. They communicated important course goals, helped to keep course participants engaged and participating in productive dialogue, and encouraged course participants to explore new concepts in this course. By integrating and combining new information, it helped students to answer questions raised in course activities. Reflection on course content 
and discussions helped students to understand fundamental concepts in class. The course professor divided the instruction into teaching, cognitive, and social presence through the activities as mentioned earlier and eventually formed a community. Fiosck (2020) stated that strong feelings of the community increase the flow of information, the availability of support, commitment to group goals, cooperation among members, and satisfaction with group efforts. Effective online learning, notably higher-order learning, is dependent on the development of a community.

Table 2. The extent of experience of the graduate students with the online distance learning environment

\begin{tabular}{ccc}
\hline Indicators & Mean & Description \\
\hline Teaching Presence & 4.70 & Very High \\
Social Presence & 4.48 & High \\
Cognitive Presence & 4.57 & Very High \\
Experiences & $\mathbf{4 . 5 8}$ & Very High \\
\hline Scale: $1.00-1.50$ Very Low; 1.51-2.50 Low; 2.51-3.50 Moderate; 3.51-4.50 High; 4.51-5.00 Very High
\end{tabular}

\subsection{Level of Satisfaction of the Graduate Students with the Online Distance Learning Environment}

Satisfaction in online learning is complex and multidimensional. It includes many factors, such as communication, student participation in online discussions, flexibility, workload, technology support, instructor pedagogical skills, and feedback ( Elshami, Taha, Abuzaid, et al., 2021). This study measured the level of satisfaction with the distance online learning environment regarding technological infrastructure, course professor, learning methodologies, course design, and evaluation system.

Table 3 indicates that the level of satisfaction of the graduate students with the distance online learning environment in the Graduate School is very high (4.56). The graduates have very high satisfaction in terms of course professor (4.67), learning methodologies (4.59), course design (4.55), and evaluation system (4.54). While high satisfaction (4.46) in technological infrastructure.

The findings above imply that the course professors are accessible and approachable and provide encouragement and guidance in online discussion and sharing of ideas. The learning methodologies they employed facilitate learning and stimulation of online interaction between faculty and students. The course design they used is relevant to current times and innovative aspect of the study plan, has adequacy of the online material and resources used, promotes the development of different types of competencies, and has adequacy of the technology and platform used. Furthermore, they used varied evaluation methods (diagnostic, formative, summative, and self-assessment) and clearly defined assessment elements and processes. Gopal, Singh, and Aggarwal (2021) stated that instructor quality, course design, prompt feedback, and expectation of students positively impact students' satisfaction, and further, student satisfaction positively impacts students' performance.

Table 3. Level of satisfaction of the graduate students with distance online learning environment

\begin{tabular}{ccc}
\hline Indicators & Mean & Description \\
\hline Technological Infrastructure & 4.46 & High \\
Course Professor & 4.67 & Very High \\
Learning Methodologies & 4.59 & Very High \\
Course Design & 4.55 & Very High \\
Evaluation System & 4.54 & Very High \\
Satisfaction & 4.56 & Very High \\
\hline Scale: $1.00-1.50$ Very Low; 1.51-2.50 Low; 2.51-3.50 Moderate; 3.51-4.50 High; 4.51-5.00 Very High
\end{tabular}

\subsection{Relationship between Respondents' Expectations, Experiences, and Satisfaction with the Online Distance Learning} Environment

The result of spearman correlation in Table 4 shows that expectation has a very high positive relationship with experiences (.772). This indicates that more expectations may lead to more experiences of the graduate students and vice versa.

There is a high positive correlation between expectation and satisfaction (.669). This shows that graduate students with higher expectations will have higher satisfaction and vice versa. The findings are supported by Umbit and Taat's (2016) study that expectation has a positive relationship and effect on students' satisfaction. When the students' expectations are achieved, it leads to a higher satisfaction level of the student. However, when students' expectations are not fulfilled, it might lead to lower learning and satisfaction with the course (Gopal, Singh, and Aggarwal,2021).

The experiences of graduate students have a very high positive correlation with satisfaction (.702). This shows that graduate students who have more experience in the school have higher satisfaction and vice versa.

Table 4. Relationship between respondents' expectations, experiences, and satisfaction with the online distance learning environment 


\begin{tabular}{ccc}
\hline Expectation to Experiences & .772 & Very High Positive Correlation \\
Expectation to Satisfaction & .669 & High Positive Correlation \\
Experiences to Satisfaction & .702 & Very High Positive Correlation \\
\hline Scale: $.000-.300$ Negligible; $.301-.500$ & Low correlation; $.501-.700$ & Moderate correlation; . $701-.900$ \\
High correlation; $.901-1.000$ Very High correlation &
\end{tabular}

\subsection{Indicators of Expectations and Experiences that Influence the Respondents' Level of Satisfaction with the Online Distance Learning Environment}

The regression analysis in Table 5a reveals that none of the indicators of expectation influence the respondent's satisfaction with the online distance learning environment of the graduate school. (-.035 to .355). This also reveals that the expectation of students does not affect their satisfaction. The study's findings contradicted Umbit and Taat's (2016) study, which stated that four elements determine students' expectations of e-learning: course design quality, interaction quality between students and lecturers, interaction quality between students and peers, and self-directed learning. Among the four elements, this study found that self-directed learning strongly impacts expectations and students' satisfaction, followed by the interaction quality between students and peers and the course design quality. Flexibility in course design plays an important role in increasing students' satisfaction towards e-learning.

Table 5a. Indicators of expectations influencing the level of satisfaction in the online learning environment of the graduate school

\begin{tabular}{cccc}
\hline Indicators & $\begin{array}{c}\text { Beta } \\
\text { Coefficient }\end{array}$ & Significance & Interpretation \\
\hline Technological & .218 & .259 & Not Significant \\
Infrastructure & .073 & .731 & Not Significant \\
Course Professor & .355 & .125 & Not Significant \\
Learning Methodologies & -.035 & .884 & Not Significant \\
Course Design & .096 & .452 & Not Significant \\
Evaluation System & & &
\end{tabular}

The regression analysis in Table $5 \mathrm{~b}$ shows that social and cognitive presence influence and affect the satisfaction to the Graduate School (.275 and .350). This indicates that an increase in the social and cognitive presence will increase the satisfaction in the distance online learning environment in Graduate School. Gray and Diloneto (2016) supported the study's findings that students with high overall perceptions of social presence scored high in terms of perceived learning and perceived satisfaction with the instructor. They suggested that it is crucial to focus on the interaction that takes place between students and instructors. Accordingly, Social presence had the most significant effect on students' satisfaction with eLearning courses.

Table 5b. Indicators of experiences influencing the extent of satisfaction in the online learning environment of the graduate school

\begin{tabular}{lccc}
\hline \multicolumn{1}{c}{ Indicators } & $\begin{array}{c}\text { Beta } \\
\text { Coefficient }\end{array}$ & Significance & Interpretation \\
\hline Teaching Presence & .137 & .346 & Not Significant \\
Social Presence & .275 & .023 & Significant \\
Cognitive Presence & .350 & .026 & Significant \\
\hline$R 2=.378 ;$ F=10.953; Sig. $=.000$ & & &
\end{tabular}

\subsection{Suggestions to Improve the Online Learning Environment in the OMSC Graduate School}

Student perceptions of the quality of their online courses and their satisfaction with them are important since these perceptions have a direct impact on their learning and motivation (Davies, Howell, \& Petrie, 2010). Student perceptions can provide an understanding of the effectiveness of student success in online courses.

Students' perceptions of their online courses' quality and satisfaction are essential since these perceptions directly impact their learning and motivation. Student perceptions can explain student success in online courses ( Sadaf, Martin, \& Delzell, 2019). In this study, suggestions to improve the distance online learning environment of OMSC graduate school were solicited from graduate students, such as technological infrastructure, course professor, learning methodologies, course design, and evaluation system.

To improve the online learning environment in terms of technological infrastructure in the Graduate School of OMSC, the respondents suggest improving internet connectivity (57\%). Internet connectivity is needed for the online class of the students. Even if the students have good internet connectivity, but the school has poor connectivity, the holding of the online class is affected. Selvanathan, Husin, \& Azazi (2020) support the findings that inadequate online learning infrastructures and limited accessibility to the internet make the online learning process harder for the students, especially in rural and isolated 
areas. Besides the limited accessibility to the internet, the students experience difficulty communicating with their lectures, interaction with their friends, and laboratory access, which affects their studies.

Table 6. Suggestions to improve the distance online learning environment in terms of technological infrastructure

\begin{tabular}{lcc}
\hline \multicolumn{1}{c}{ Indicators } & Frequency & Percentage \\
\hline Improve internet connectivity - & 33 & $57 \%$ \\
Create a cloud database for all references & 1 & $2 \%$ \\
Use asynchronous \& synchronous & 1 & $2 \%$ \\
Make computer laboratory accessible to all & 1 & $2 \%$ \\
Use other platforms that consume less data & 1 & $2 \%$ \\
Identify and support struggling students in digital learning & 1 & $2 \%$ \\
Remove the other miscellaneous fees since we are online & 1 & $2 \%$ \\
Use other Learning Management System & 1 & $2 \%$ \\
None & 18 & $31 \%$ \\
Total & 58 & $100 \%$ \\
\hline
\end{tabular}

To improve the distance online learning environment in terms of course professors, the respondents suggest they must keep up their good work because they are all excellent (26\%). Furthermore, professors must use a platform that encourages teacher-student interaction (9\%), and professors must be considerate (9\%). Gopal, Singh, and Aggarwal (2021) support the findings that instructor quality plays an essential role in affecting the students' satisfaction in online classes. Instructor quality refers to a professional who understands the students' educational needs, has unique teaching skills, and understands how to meet the students' learning needs.

Table 6b. Suggestion to improve the online learning environment in terms of the course professor

\begin{tabular}{lcc}
\multicolumn{1}{c}{ Indicators } & Frequency & Percentage \\
\hline Discuss their methods of assessment with the students & 1 & $2 \%$ \\
Invite resource speakers & 1 & $2 \%$ \\
Use online platforms that encourage teacher-student interaction & 5 & $9 \%$ \\
Give adequate assistance for online learning & 1 & $2 \%$ \\
Professors must be considerate & 5 & $9 \%$ \\
Professors must keep up their good work; they are all excellent. & 15 & $25 \%$ \\
None & 30 & $51 \%$ \\
Total & 58 & \\
\hline
\end{tabular}

To improve the online learning environment in terms of learning methodologies, the respondents suggested the use of asynchronous and modular methods (26\%), using relevant teaching strategies that apply to the new normal (14\%), employing other strategies aside from reporting (9\%). The learning methodologies need improvement (9\%).

Table 6c. Suggestions to improve the online learning environment in terms of learning methodologies

\begin{tabular}{lcc}
\hline \multicolumn{1}{c}{ Indicators } & Frequency & Percentage \\
\hline Needs Improvement & 5 & $9 \%$ \\
Employ other strategies aside from reporting & 5 & $9 \%$ \\
Use relevant teaching strategies that apply to the new normal & 8 & $14 \%$ \\
Use asynchronous and modular & 15 & $26 \%$ \\
None & 25 & $43 \%$ \\
Total & 58 & $100 \%$ \\
\hline
\end{tabular}

Based on Table 6d, the respondents have no suggestion to improve the online learning environment regarding course design. This implies that the majority of the respondents were satisfied with the course design. However, three suggestions were raised, like aligning course design with the field of specialization, making the course design organized, and incorporating more helpful learning strategies. Course design and course quality have a substantial effect on satisfaction in online learning: students are more satisfied with well-designed online courses that have clear goals and are easy to navigate (Ghaderizefreh \& Hoover,2018).

As Sadaf, Martin, \& Delzell (2019) suggested, to improve online learning experiences, instructors can use the syllabus or course introductions to specifically explain how different course activities are aligned with the learning objectives. In addition, instructors can incorporate collaborative learning activities, such as problem-based learning or case-based learning, to create a community of learners through peer-to-peer interactions. Students can interact with the course content and each other through discussion boards, group work, peer review, which encourage students to work together and be active 
participants in the learning process.

Table 6d. Suggestion to improve the distance online learning environment in terms of course design

\begin{tabular}{lcc}
\hline \multicolumn{1}{c}{ Indicators } & Frequency & Percentage \\
\hline Align course design with the field of specialization & 1 & $2 \%$ \\
Make the course design organized. & 1 & $2 \%$ \\
Incorporate more and useful learning strategies & 1 & $2 \%$ \\
None & 55 & $95 \%$ \\
Total & 58 & $100 \%$ \\
\hline
\end{tabular}

The suggestions to improve the distance online learning environment in terms of evaluation system include the return and give feedback on students outputs (12\%), timely submission of grades (9\%), and use different evaluation methods (7\%). Furthermore, Gopal, Singh, and Aggarwal (2021) also mentioned that feedback gives information about the students' effective performance. Prompt feedback enhances the student learning experience and boosts satisfaction. Prompt feedback is the self-evaluation tool for the students by which they can improve their performance.

Table 6e. Suggestions to improve the online learning environment in terms of the evaluation system

\begin{tabular}{lcc}
\multicolumn{1}{c}{ Indicators } & Frequency & Percentage \\
\hline Use different evaluation methods & 4 & $7 \%$ \\
Return and give feedback on students outputs & 7 & $12 \%$ \\
Give enough activities & 2 & $3 \%$ \\
Timely submission of grades & 5 & $9 \%$ \\
Discuss the evaluation system with the students & 3 & $5 \%$ \\
None & 37 & $64 \%$ \\
Total & 58 & $100 \%$ \\
\hline
\end{tabular}

The findings of this study imply that the distance online learning environment in OMSC Graduate School required improvement, especially in terms of the quality of the interaction and instruction delivered during the course. Even though the respondents are satisfied with the instructor, course management, and technology dimension, some improvements should be implemented in learning methodologies and evaluation systems to enhance online teaching and learning delivery.

\section{Conclusions}

This study was conducted to determine the expectations, experiences, and satisfaction of the Graduate students with distance online learning environment in Occidental Mindoro State College during the Covid -19 pandemic. Based on the study's findings, it was concluded that the majority of the graduate students have high expectations in technological infrastructure and very high expectations with the distance online learning environment in terms of course professor, learning methodologies, and course design. In addition, the graduate students have a very favorable experience in the distance online learning environment, specifically teaching and cognitive presence. Therefore, the graduate students are very satisfied with the distance online learning environment of the graduate school, specifically in the course professor, learning modalities, course designs, and evaluation system. High expectations and favorable experiences lead to satisfaction in the distance online learning environment. The expectation of the graduate students does not affect their satisfaction. At the same time, social and cognitive presence increases the graduate students' satisfaction with the distance online learning environment of the OMSC Graduate School. Therefore, there is a need for concrete actions to improve and optimize the processes in the distance learning environment to enhance students' experiences and increase the level of satisfaction.

\section{Recommendations}

Based on the findings mentioned above and the study's conclusions, the following recommendations are presented: The OMSC Graduate School may continue to use the online distance learning since the students have favorable experiences and highly satisfied with this flexible delivery mode. Improve the technological infrastructure by designing, investing, and maintaining online educational platforms to provide the students with a suitable and reliable distance online environment they need. Maintain favorable experiences and sustain the high satisfaction level in the distance learning environment. Explore alternative learning modes like asynchronous and modular learning, using various teaching strategies and tools that spark students' interest and engagement, and providing information and feedback in multiple ways. Sustain teaching, social, and cognitive presence by improving teachers' technical skills and developing training programs to help teachers remodel and 
adapt their teaching style and interact with students in the online environment. Future studies along this line may be conducted by involving other stakeholders such as teachers and parents.

\section{References}

Arbaugh, J. B., Cleveland-Innes, M., Diaz, S.R., Garrison, D.R., Ice, P., Richardson, \& Swan, K.P. (2008). Developing a community of inquiry instrument: Testing a measure of the Community of Inquiry framework using a multiinstitutional sample. The Internet and Higher Education, 11(3-4), 133-136. https://www.sciencedirect.com/science/article/abs/pii/S1096751608000250.

Arslan, Daghan, \& Akkoyunlu (2020). Adaptation of the Student Expectations of Online Learning Survey Revised (SEOLSR) into Turkish. Turkish Journal of Computer and Mathematics Education (TURCOMAT). 11(2). https://doi.org/10.17762/turcomat.v11i2.238.

Bailie, J. L. (2015). Perceptions and expectations of online graduate students regarding synchronous events. Journal of Instructional Pedagogies 17. https://files.eric.ed.gov/fulltext/EJ1102866.pdf.

Bektashi, L. (2018). Community of Inquiry Framework in Online Learning: Use of Technology. https://techandcurriculum.pressbooks.com/chapter/coi-and-online-learning/.

Chen, T. , Peng ,L., Yin, X., Rong, J. ,Yang, J. , \& Cong, G. (2020). Analysis of User Satisfaction with Online Education Platforms in China during the COVID-19 Pandemic. Healthcare 8 (3). https://doi.org/10.3390/healthcare8030200.

Di Pietro,G., Biagi F., Costa ,P., Karpinski, Z., \& Mazza ,J. (2020). The likely Impact of COVID-19 on Education: Reflections Based on the Existing Literature and Recent International Datasets. http://dx.doi.org/10.2760/126686 .

Dziuban,D., Moskal, P., Thompson, J., Kramer, L., De Cantis, G., \& Hermsdorfer,A. (2015). Student Satisfaction with Online Learning: Is it a Psychological Contract? https://files.eric.ed.gov/fulltext/EJ1062943.pdf.

Elshami,W., Taha,M.H., Abuzaid, M., et al (2021). Satisfaction with online learning in the new normal: the perspective of students and faculty at medical and health sciences college. Med Educ Online. https://www.tandfonline.com/doi/full/10.1080/10872981.2021.1920090.

Fiock, H. S. (2020). Designing a Community of Inquiry in Online Courses. International Review of Research in Open and Distributed Learning, 21(1). https://doi.org/10.19173/irrodl.v20i5.3985.

Fry, M. (2019). Perceptions and Experiences of Online Learning and Synchronous Communication.https://digitalcommons.nl.edu/cgi/viewcontent.cgi? article=1457\&context=diss.

Garrison, D. R., Anderson, T., \& Archer, W. (2000). Critical inquiry in a text-based environment: Computer conferencing in higher education model. The Internet and Higher Education, 2(2-3), 87-105.http://dx.doi.org/10.1016/S10967516(00)00016-6

Ghaderizefreh S., \& Hoover, M. (2018). Student Satisfaction with Online Learning in a Blended Course. International Journal of Digital Society (IJDS), 9(3). https://infonomics-society.org/wp-content/uploads/ijds/publishedpapers/volume-9-2018-2/Student-Satisfaction-with-Online-Learning-in-a-Blended-Course.pdf.

Gopal, R., Singh, V., \& Aggarwal, A. (2021) Impact of online classes on the satisfaction and performance of students during the pandemic period of COVID 19. Educational and Information Technologies . https://doi.org/10.1007/s10639-021$10523-1$

Lemos, S., \& Pedro,N. (2012). Students' Expectation and Satisfaction in Postgraduate Online Courses. http://www.icicte.org/Proceedings2012/Papers/14-3-Lemos.pdf.

Kusel, J., Martin, F., \& Markic, S. ( 2020) Students' Readiness for Using Digital Media and Online Learning — Comparison between Germany and the USA. https://www.mdpi.com/2227-7102/10/11/313.

Nwankwo, A.A. (2015). Students' Learning Experiences and Perceptions of Online Course Content and Interactions. Walden Dissertations and Doctoral Studies. 188. https://scholarworks.waldenu.edu/dissertations/188.

Sadaf, Martin, \& Delzell (2019). Student Perceptions of the Impact of Quality Matters-Certified Online Courses on Their Learning and Engagement. Online Learning Journal. http://dx.doi.org/10.24059/olj.v23i4.2009.

Selvanathan,M., Husin,N.A.M., \& Azazi, N.A.N (2020). Students learning experiences during COVID-19: Work from home period in Malaysian Higher Learning Institutions. Sage Journals. https://doi.org/10.1177/0144739420977900.

Sunkara, V.M., \& Kurra, R.R. (2017). An Analysis of Learner Satisfaction and Needs

on E-Learning Systems. International Journal of Computational Intelligence Research ISSN $0973-187313$ (3). https://www.ripublication.com/ijcir17/ijcirv13n3_09.pdf.

Umbit , A.F. \& Taat, M.H. (2016). The Effects of Expectations and Satisfaction towards E-Learning among Students. Journal of Modern Education Review. 6(9) . https://doi.org/10.15341/JMER\%2821557993\%29\%2F09.06.2016\%2F004,

Wart, V. M., Ni, A., Medina, P. et al. (2020). Integrating students' perspectives about online learning: a hierarchy of factors. International Journal Educational Technology in Higher Education . 17 (53) . https://doi.org/10.1186/s41239-02000229-8 